\title{
Knowledge, Attitudes, and Practices of 50 Patients with Surgically Treated Cystic Echinococcosis from Basrah Province, Iraq
}

\author{
Mohanad Faris Abdulhameed ${ }^{1,2}$, Ian Duncan Robertson ${ }^{1,3}$, Suzan Ali Al-Azizz ${ }^{2}$, Ihab Habib ${ }^{1,4^{*}}$ \\ ${ }^{1}$ School of Veterinary Medicine, Murdoch University, Perth, Australia \\ ${ }^{2}$ College of Veterinary Medicine, University of Basrah, Basrah, Iraq \\ ${ }^{3}$ China-Australia Joint Research and Training Center for Veterinary Epidemiology, Huazhong Agricultural University, Wuhan, China \\ ${ }^{4}$ High Institute of Public Health, Alexandria University, Alexandria, Egypt
}

\section{ARTICLE INFO}

\section{Article History}

Received 20 February 2018

Accepted 28 April 2018

Keywords

Cystic echinococcosis

hydatid disease

Iraq

\begin{abstract}
Cystic echinococcosis (CE) is recognised worldwide as a neglected disease of public health concern, particularly in low- and middle-income countries. The objectives of this study were to describe, using a questionnaire survey, the characteristics, attitudes, knowledge, and practices of patients with CE from Basrah Province, Iraq. We interviewed 50 patients, 31 female and 19 male, of whom, $74 \%$ originated from rural areas. Approximately half (48\%) of the participants reported slaughtering livestock at home for their families' consumption; 78\% indicated the presence of a large number of stray dogs roaming freely about their village; $86 \%$ reported that they never boiled water prior to drinking it; and $26 \%$ reported not washing vegetables prior to eating them. Although a large proportion of the participants $(72 \%)$ had heard of hydatid disease prior to becoming ill, over half (57\%) were not aware how the disease was transmitted from animals to humans. This study highlighted a gap in health education efforts regarding CE in Southern Iraq, with a lack of counselling of patients on how to prevent reinfection. An intensive control programme should be implemented and founded on health education to reduce CE disease in Basrah.
\end{abstract}

(c) 2018 Atlantis Press International B.V This is an open access article under the CC BY-NC license (http://creativecommons.org/licenses/by-nc/4.0/).

\section{INTRODUCTION}

Cystic echinococcosis (CE) is a neglected disease of public health significance worldwide, especially in low- and middle-income countries [1]. The disease is caused by a tapeworm belonging to the genus Echinococcus that is transmitted between carnivores (dogs and wolves: the definitive hosts) and primarily livestock (the intermediate hosts). Humans accidentally acquire the infection usually through consuming food or water contaminated with eggs shed by the definitive host [2]. Once ingested by an intermediate host, the eggs hatch in the small intestine, releasing oncospheres that penetrate the intestinal wall and circulate in the bloodstream to finally lodge in a vital organ where the cysts slowly grow over a period of several years [3]. Approximately $70 \%$ of cysts in humans are found in the liver and $20 \%$ in the lungs $[4,5]$.

The highest prevalence of CE in humans is typically found in sheep-raising rural communities, as sheep are considered the most important intermediate host. In addition, the emergence of human echinococcosis may be attributed to a change in the local ecology and increasing urbanisation, resulting in exposure of people to infected dogs $[6,7]$. Several studies have highlighted the role of sociodemographic characteristics, including age, gender, occupation, and level of education, as important factors in the transmission of echinococcosis to humans [8-10].
In Iraq, CE is regarded as a major public health concern [11]. The highest numbers of human cases have been reported in the provinces of Central and Southern Iraq including Basrah, Nasiriyah, and Muthana [12-14]. In our recent research, we reviewed hospitalisation records from Basrah from January 2005 to December 2015 , and estimated an annual clinical incidence of CE of 4.5 cases per 100,000 people [15]. In general, treatment of echinococcosis in humans is costly and complicated and needs prolonged postoperative health care [16]. Hence, it is important to ensure that people living in endemic communities receive appropriate health education on how to protect themselves from infection. Understanding the level of knowledge and awareness of the disease in previously infected individuals is an important step in identifying potential gaps in knowledge prior to developing health education programmes. In an endemic setting, such as in Iraq, failure to understand these gaps results in an increased burden on the public health system. The objectives of this study were to describe the characteristics, attitudes, knowledge, and practices of a cohort of patients who had undergone surgery as a result of CE in Basrah, Iraq.

\section{MATERIALS AND METHODS}

\subsection{Study Setting}

Basrah is the third largest province in Iraq and lies in the south of the country, bordering Iran, Kuwait, and Saudi Arabia. 
The human population in Basrah was estimated at 2.4 million in 2014, with $20.1 \%$ of this being rural [17]. The province contains almost 140,000 livestock (data obtained from the Veterinary Hospital of Basrah, Ministry of Agriculture, based on the last census of livestock conducted in Basrah in 2015). In Basrah, there are six hospitals (five public and one private) that have facilities and skilled surgeons to operate on human cases of CE.

\subsection{Case Recruitment and Questionnaire Administration}

This research was approved by the Human Ethics Review Committee of Murdoch University, Perth, Australia (Permission number: 2016/034). Official written approval to review hospital records and to contact patients was obtained from the Ministry of Health in Iraq and from the Basrah Health Directorate. Of six hospitals in Basrah from which previous incidence data had been collected [15], four gave permission to interview hospitalised patients with CE after surgical intervention, or to contact patients who had undergone surgery between 2014 and 2016. The hospitals were visited four times a week from May to July 2016, and 19 current patients were recruited. A further 31 discharged patients were also approached and they agreed to participate. A questionnaire was administered either at the hospital (face-to-face) for the 19 current patients or via telephone interview for the 31 discharged patients. Prior to administering the questionnaire, a verbal explanation of the study was given and oral consent was obtained from all participants. The parents/guardians of two female patients (aged 4 and 10 years) were interviewed on behalf of the children. The questionnaire contained 30 questions and focused on demographic characteristics of the patients and their knowledge, attitudes, and practices relating to $\mathrm{CE}$. The questionnaire, which included both closed and open-ended questions, was developed in English and then translated and delivered in Arabic by native speakers. A copy of the questionnaire can be obtained from the corresponding author.

\subsection{Data Analysis}

Questionnaire data were entered into a spreadsheet (Microsoft Excel, 2013) and descriptive analyses were undertaken using SPSS version 20 (SPSS Inc, Chicago, USA). The frequencies, percentages, and $95 \%$ confidence intervals (CI) for responses were calculated.

\section{RESULTS}

\subsection{Anatomical Distribution of Cysts in the Surveyed Patients}

Sixty cysts were surgically excised from the 50 participants with $31(51.7 \%)$ in the liver and $17(28.3 \%)$ in the lungs (Table 1). There was no significant difference in the location of cysts between women and men. Most patients (82\%) only had one organ affected, $16 \%$ had cysts in two organs, and only one patient had three organs affected.

\subsection{Sociodemographic Characteristics of Patients with CE}

The age of patients with CE ranged from 4 to 72 years (median: 39.5 years, standard deviation: 14.8 years) (Table 2). About $10 \%$ of the patients reported having another family member (not surveyed) also diagnosed with CE. Thirty-seven (74\%) patients originated from a rural area, $42 \%$ had only obtained a primary school level of education, and $24 \%$ had never been to school. Approximately

Table 1 Anatomical sites of hydatid cysts as reported by 50 patients

\begin{tabular}{lcccc}
\hline & Female & Male & Total (\%) & $\boldsymbol{p}$-Value \\
\hline Organs involved & & & & 0.97 \\
Lung & $10(25.6)^{\mathrm{a}}$ & $7(33.3)^{\mathrm{a}}$ & $17(28.3)$ & \\
Liver & $18(46.1)^{\mathrm{a}}$ & $13(61.9)^{\mathrm{a}}$ & $31(51.7)$ & \\
Urinary bladder & $1(2.5)$ & $1(4.7)$ & $2(3.3)$ & \\
Spleen & $4(10.2)^{\mathrm{a}}$ & 0 & $4(6.7)$ & \\
Kidney & $2(5.1)^{\mathrm{a}}$ & 0 & $2(3.3)$ & \\
Ovary & $2(5.1)$ & 0 & $2(3.3)$ & \\
Pancreas & $1(2.5)$ & 0 & $1(1.7)$ & \\
Intestine & $1(2.5)$ & 0 & $1(1.7)$ & \\
Total & $39(65.0)$ & $21(35.0)$ & 60 & \\
Number of organs & & & & \\
$\quad$ affected in patients & & & & \\
1 & $24(77.4)$ & $17(89.4)$ & $41(82.0)$ & \\
2 & $6(19.3)$ & $2(10.5)$ & $8(16.0)$ & \\
3 & $1(3.2)$ & 0 & $1(2.0)$ & \\
Total & $31(62.0)$ & $19(38.0)$ & 50 & \\
\hline
\end{tabular}

aAs some patients had more than one organ affected, the total number of organs involved was $>50$.

Table 2 Sociodemographic characteristics of 50 patients with CE in Basrah Province, Iraq

\begin{tabular}{|c|c|c|c|c|}
\hline Variables & Category & $n$ & $\begin{array}{c}\text { Percentage } \\
(95 \% \text { CI })\end{array}$ & $p$-Value \\
\hline \multirow[t]{2}{*}{ Sex } & Female & 31 & $62(47.2-75.3)$ & \multirow[t]{2}{*}{0.22} \\
\hline & Male & 19 & $38(24.7-55.8)$ & \\
\hline \multirow[t]{7}{*}{ Age of patients (y) } & $<10$ & 2 & $4(0.5-13.7)$ & \multirow[t]{7}{*}{0.99} \\
\hline & $11-20$ & 5 & $10(3.3-21.8)$ & \\
\hline & $21-30$ & 10 & $20(10.0-33.7)$ & \\
\hline & $31-40$ & 10 & $20(10.0-33.7)$ & \\
\hline & $41-50$ & 14 & $28(16.2-42.5)$ & \\
\hline & $51-60$ & 6 & $12(4.5-24.3)$ & \\
\hline & $>61$ & 3 & $6(1.3-16.5)$ & \\
\hline \multirow{2}{*}{$\begin{array}{c}\text { Has any other member } \\
\text { in your family been } \\
\text { diagnosed with CE? }\end{array}$} & Yes & 5 & $10(3.3-21.8)$ & \multirow[t]{2}{*}{1.27} \\
\hline & No & 45 & $90(78.2-96.7)$ & \\
\hline \multirow[t]{2}{*}{ Location } & Rural & 37 & $74(59.7-85.4)$ & \multirow[t]{2}{*}{0.01} \\
\hline & Urban & 13 & $26(14.6-40.3)$ & \\
\hline \multirow[t]{5}{*}{ Education level } & Never went to school & 12 & $24(13.1-38.2)$ & \multirow[t]{5}{*}{1.00} \\
\hline & Literacy class only & 5 & $10(3.3-21.8)$ & \\
\hline & Primary & 21 & $42(28.2-56.8)$ & \\
\hline & Secondary & 10 & $20(10.0-33.7)$ & \\
\hline & College & 2 & $4(0.5-13.7)$ & \\
\hline \multirow[t]{6}{*}{ Occupation } & Public servant & 2 & $4(0.5-13.7)$ & \multirow[t]{6}{*}{0.99} \\
\hline & Farmer & 8 & $16(7.2-29.1)$ & \\
\hline & Housewife & 27 & $54(39.3-68.2)$ & \\
\hline & Student & 2 & $4(0.5-13.7)$ & \\
\hline & Unemployed & 6 & $12(4.5-24.3)$ & \\
\hline & Other & 5 & $10(3.3-21.8)$ & \\
\hline
\end{tabular}

CE, cystic echinococcosis; CI, confidence interval. 
half $(54 \%)$ of the patients ( $87 \%$ of female patients) undertook domestic duties, $16 \%$ of all patients were farmers ( $42 \%$ of male patients), and $12 \%$ were unemployed.

\subsection{Practices Adopted by Patients with CE}

Table 3 summarises the practices adopted by patients with CE. Twenty (40\%) of the surveyed patients owned one or more dogs. Of these, six reported allowing their dogs to roam freely, while five reported tying up their dogs within $50 \mathrm{~m}$ of their house. About $40 \%$ of dog owners never allowed their dog access to the kitchen or food preparation area, and 50\% never allowed their dog access to water storage containers. About $60 \%$ of dog owners reported feeding raw offal to their dogs.

The majority of patients (78\%) reported the presence of a large number of dogs roaming freely about their village. Approximately half $(48 \%)$ of the participants had slaughtered livestock at home, and no one had contacted a veterinarian when they had observed/ detected a cyst or lesion characteristic of CE in the viscera of the slaughtered animals. The majority $(86 \%)$ of the participants

Table 3 Patient practices toward cystic echinococcosis in Basrah Province, Iraq

\begin{tabular}{|c|c|c|c|c|}
\hline Questions & Response categories & $n$ & $\begin{array}{l}\text { Percentage } \\
(95 \% \mathrm{CI})\end{array}$ & $p$-Value \\
\hline \multirow[t]{2}{*}{ Do you own a dog? } & Yes & 20 & $40(26.4-54.8)$ & 0.31 \\
\hline & No & 30 & $60(45.2-73.6)$ & \\
\hline \multirow[t]{2}{*}{ If you own a dog, is it tied up? } & Yes & 6 & $30(11.9-54.3)$ & 0.19 \\
\hline & No & 14 & $70(45.7-88.1)$ & \\
\hline \multirow[t]{2}{*}{ If the dog is tied up, where is it tied up? } & Far $(>50 \mathrm{~m})$ from my dwelling & 1 & $16.7(0.4-64.1)$ & 0.22 \\
\hline & Near $(<50 \mathrm{~m})$ to my dwelling & 5 & $83.3(53.9-99.6)$ & \\
\hline \multirow{5}{*}{$\begin{array}{l}\text { Does your dog have access to the kitchen } \\
\text { area/food preparation area? }\end{array}$} & Never & 8 & $40(19.1-63.9)$ & 1.00 \\
\hline & Rarely & 2 & $10(1.2-31.7)$ & \\
\hline & Sometimes & 6 & $30(11.9-54.3)$ & \\
\hline & Often & 2 & $10(1.2-31.7)$ & \\
\hline & Always & 2 & $10(1.2-31.7)$ & \\
\hline \multirow{5}{*}{$\begin{array}{l}\text { Does your dog have access to containers used to } \\
\text { store human drinking water? }\end{array}$} & Never & 10 & $50(27.2-72.8)$ & 1.00 \\
\hline & Rarely & 2 & $10(1.2-31.7)$ & \\
\hline & Sometimes & 7 & $35(15.4-59.2)$ & \\
\hline & Often & 1 & $5.0(0.1-24.9)$ & \\
\hline & Always & 0 & $0.0(0.9-16.8)$ & \\
\hline \multirow{5}{*}{$\begin{array}{l}\text { How often do you feed your dog raw offal } \\
\text { (e.g., liver or lung)? }\end{array}$} & Never & 8 & $40(19.1-63.9)$ & 1.00 \\
\hline & Rarely & 1 & $5(0.1-24.9)$ & \\
\hline & Sometimes & 5 & $25(8.7-49.1)$ & \\
\hline & Often & 4 & $20(5.7-43.7)$ & \\
\hline & Always & 2 & $10(1.2-31.7)$ & \\
\hline \multirow{2}{*}{$\begin{array}{l}\text { Have you seen stray dogs in your neighbourhood } \\
\text { over the last week? }\end{array}$} & Yes & 39 & $78(64.0-88.5)$ & 0.03 \\
\hline & No & 11 & $22(11.5-36.0)$ & \\
\hline \multirow[t]{2}{*}{ Do you own livestock? } & Yes & 22 & $44(30.0-58.7)$ & 0.54 \\
\hline & No & 28 & $56(41.3-70.0)$ & \\
\hline \multirow[t]{2}{*}{ Do you slaughter livestock at your home? } & Yes & 24 & $48(33.7-62.6)$ & 0.84 \\
\hline & No & 26 & $52(37.4-66.3)$ & \\
\hline \multirow{2}{*}{$\begin{array}{l}\text { Do you always call an inspector (vet or meat } \\
\text { inspector) if there is a cyst in the slaughtered carcass? }\end{array}$} & Yes & 0 & $0.0(0.0-14.3)$ & 6.33 \\
\hline & No & 24 & $48(27.4-69.1)$ & \\
\hline \multirow[t]{4}{*}{ What is the main source of family drinking water? } & Reverse osmosis & 36 & $72(57.5-83.8)$ & 0.01 \\
\hline & Tanker & 9 & $18(8.6-31.4)$ & \\
\hline & Tap water & 4 & $8(2.2-19.2)$ & \\
\hline & Well & 1 & $2(0.1-10.6)$ & \\
\hline \multirow[t]{4}{*}{ Do you boil water before drinking it? } & Never & 43 & $86(73.3-94.2)$ & 0.02 \\
\hline & Some of the time & 4 & $8(2.2-19.2)$ & \\
\hline & Most of the time & 2 & $4(0.5-13.7)$ & \\
\hline & All the time & 1 & $2(0.1-10.6)$ & \\
\hline \multirow[t]{2}{*}{ How is your family's drinking water stored? } & Stored in covered containers & 45 & $90(78.2-96.7)$ & 1.27 \\
\hline & Stored in uncovered containers & 5 & $10(3.3-21.8)$ & \\
\hline \multirow{5}{*}{$\begin{array}{l}\text { How often do you eat leafy vegetables without first } \\
\text { washing them? }\end{array}$} & Never & 13 & $26(14.6-40.3)$ & 1.00 \\
\hline & Rarely & 4 & $8(2.2-19.2)$ & \\
\hline & Sometimes & 20 & $40(26.4-54.8)$ & \\
\hline & Often & 4 & $8(2.2-19.2)$ & \\
\hline & Always & 9 & $18(8.6-31.4)$ & \\
\hline \multirow{4}{*}{$\begin{array}{l}\text { For lettuce and other leafy vegetables, how would you } \\
\text { prepare them as part of your salad? }\end{array}$} & Wash it under running water only & 36 & $72(57.5-83.8)$ & 0.01 \\
\hline & Soak in water in the sink & 10 & $20(10.0-33.7)$ & \\
\hline & Wash it with detergent & 3 & $6(1.3-16.5)$ & \\
\hline & Peel outer leaves and eat the rest & 1 & $2(0.1-10.6)$ & \\
\hline
\end{tabular}

CI, confidence interval. 
reported that they never boiled water prior to drinking it; however, most participants (90\%) did store their water in covered containers. Twenty-six participants never washed vegetables prior to eating them, $8 \%$ rarely washed vegetables, and $40 \%$ reported that they sometimes washed vegetables.

\subsection{Knowledge and Attitudes of Patients with CE}

Patients' knowledge about hydatid cysts and their attitudes toward handling potentially infected organs of slaughtered animals are outlined in Table 4 . The majority of participants (72\%) had not heard about hydatid cysts prior to surgery, and 57\% were not aware how the disease was transmitted. Most patients (70\%) reported that they had not received any information on how they may have become infected with CE. Furthermore, $86 \%$ of patients reported that they had not received any advice on methods to prevent reinfection by hydatid cysts from medical staff at the hospital where they were operated upon.

Half of the participants (50\%) who detected organs that were unsuitable for human consumption in livestock that they slaughtered would consider feeding those affected organs to their dogs. Similarly, $54 \%$ of the respondents would consider throwing organs unsuitable for human consumption into their uncovered domestic garbage. Over half of the participants would definitely not burn affected organs, and around 60\% would not bury any organs that were considered unsuitable for human consumption.

\section{DISCUSSION}

The purpose of this descriptive study was to determine sociodemographic characteristics, household practices, and attitudes in
50 patients with CE. Among the patients with CE enrolled in this study, cysts were most commonly reported in the liver and lungs, as reported previously [18].

In this study, $62 \%$ of patients were female. Women may be more frequently exposed to the infection than men due to being involved with activities such as feeding dogs and preparing food for the family. A higher occurrence of CE in women has similarly been reported in other countries including Jordan, Tunisia, and Iran [19-21].

In this survey, $40 \%$ of the patients affected with $\mathrm{CE}$ owned one or more dogs, and of these, $60 \%$ reported feeding them raw offal. The close association of people with dogs, combined with feeding offal, enhances the likelihood of transmission of this zoonotic tapeworm along with environmental contamination [22,23].

The majority of patients (78\%) reported the presence of large numbers of dogs roaming freely in their village. Stray or free-roaming dogs are considered a major source of CE for humans [24]. A study conducted by Buishia et al. [25] in Tripoli, Libya reported that $25.8 \%$ of stray dogs had Echinococcus granulosus, primarily arising from access to offal and scavenging from dead animals. It is important that the veterinary services in Basrah undertake steps to reduce the number of stray dogs that constitute a major public health concern, not only for echinococcosis but other zoonotic diseases such as rabies and toxocariasis [26,27]. A control programme should also be developed and implemented involving dosing domestic and stray dogs with anthelmintics containing praziquantel. In Western China, monthly dosing of stray dogs over a 4-year period with praziquantel resulted in a reduction in the prevalence of infected dogs from $18.6 \%$ to $0 \%$ [28].

Around $50 \%$ of the participants reported slaughtering animals at home for household consumption. Other regional studies have highlighted the common practice of slaughtering animals by householders in or near their homes $[10,29]$. However slaughtering animals in an

Table 4 Knowledge and attitudes of patients infected with cystic echinococcosis in Basrah Province, Iraq

\begin{tabular}{|c|c|c|c|c|}
\hline Variables & Category & $n$ & Percentage $(95 \% \mathrm{CI})$ & $p$-Value \\
\hline \multirow{2}{*}{$\begin{array}{l}\text { Before getting sick, had you heard about cystic } \\
\text { echinococcosis or hydatid cyst disease? }\end{array}$} & Yes & 14 & $28(16.2-42.5)$ & \multirow[t]{2}{*}{0.02} \\
\hline & No & 36 & $72(57.5-83.8)$ & \\
\hline \multirow{4}{*}{$\begin{array}{l}\text { How do you believe cystic echinococcosis or hydatid } \\
\text { cyst disease can be caught? }\end{array}$} & Not sure & 8 & $57(28.9-82.3)$ & \multirow[t]{4}{*}{0.11} \\
\hline & Dog & 1 & $7.14(0.2-33.9)$ & \\
\hline & Food & 4 & $28.57(8.4-58.1)$ & \\
\hline & Water & 1 & $7.14(0.2-33.9)$ & \\
\hline \multirow{2}{*}{$\begin{array}{l}\text { Did your doctor, nurse, or other medical staff explain } \\
\text { how you became infected with a hydatid cyst? }\end{array}$} & Yes & 15 & $30(17.9-44.9)$ & \multirow[t]{2}{*}{0.04} \\
\hline & No & 35 & $70(55.4-82.1)$ & \\
\hline \multirow{2}{*}{$\begin{array}{l}\text { Did your doctor, nurse, or other medical staff explain } \\
\text { ways of how to protect yourself from further infection? }\end{array}$} & Yes & 7 & $14(5.8-26.7)$ & \multirow[t]{2}{*}{0.01} \\
\hline & No & 43 & $86(73.3-94.2)$ & \\
\hline \multirow{3}{*}{$\begin{array}{l}\text { Would you feed organs not suitable for human } \\
\text { consumption to your dog? }\end{array}$} & Would definitely consider doing it & 10 & $50(27.2-72.8)$ & \multirow[t]{3}{*}{0.46} \\
\hline & Might consider doing it & 7 & $35(15.4-59.2)$ & \\
\hline & Would definitely not do it & 3 & $15(3.2-37.9)$ & \\
\hline \multirow{3}{*}{$\begin{array}{l}\text { Would you throw organs not suitable for human } \\
\text { consumption into a communal open rubbish area? }\end{array}$} & Would definitely consider doing it & 13 & $54.17(32.8-74.4)$ & \multirow[t]{3}{*}{0.08} \\
\hline & Might consider doing it & 9 & $37.50(18.8-59.4)$ & \\
\hline & Would definitely not do it & 2 & $8.33(1.0-27.0)$ & \\
\hline \multirow{3}{*}{$\begin{array}{l}\text { Would you burn organs not suitable for human } \\
\text { consumption? }\end{array}$} & Would definitely consider doing it & 1 & $4.17(0.1-21.1)$ & \multirow[t]{3}{*}{0.02} \\
\hline & Might consider doing it & 9 & $37.50(18.8-59.4)$ & \\
\hline & Would definitely not do it & 14 & $58.33(36.6-77.9)$ & \\
\hline \multirow{3}{*}{$\begin{array}{l}\text { Would you bury organs not suitable for human } \\
\text { consumption? }\end{array}$} & Would definitely consider doing it & 2 & $8.33(1.0-27.0)$ & \multirow[t]{3}{*}{0.07} \\
\hline & Might consider doing it & 8 & $33.33(15.6-55.3)$ & \\
\hline & Would definitely not do it & 14 & $58.33(36.6-77.9)$ & \\
\hline
\end{tabular}

CI, confidence interval. 
abattoir, under the supervision of a veterinarian, reduces the opportunity for the completion of the Echinococcus life cycle, through ensuring appropriate disposal of affected offal [30], as well as reducing exposure of humans to other zoonotic pathogens [31].

Although $86 \%$ of the participants reported that they never boiled water prior to drinking it, $90 \%$ did store water in covered containers. Keeping water safe and away from free-roaming dogs would help reduce the potential transmission of disease [32]. Studies in Jordan [33] and Kenya [34] established that contaminated drinking water was a risk factor for human $\mathrm{CE}$, and detected Echinococcus eggs in water used by both people and livestock. Consequently, treatment of water prior to drinking is an important process to minimise the risk of disease transmission.

In this study, $26 \%$ of participants never washed vegetables prior to consumption. A similar study in Jordan involving 55 patients infected with CE, revealed that, in addition to contact with animals through their occupation, many also consumed raw vegetables [35]. Eating unwashed vegetables is a risky practice that potentially increases exposure to Echinococcus, as well as other canine zoonotic diseases [36,37]. A study in Turkey identified a variety of canine parasite eggs on unwashed vegetables, including Taenia spp. (3.5\%), Toxocara spp. (1.5\%) and Ascaris lumbricoides (1.0\%) [38]. Low level of awareness and less knowledge about eating unwashed vegetables are considered to be important factors for acquisition of CE in humans [39].

Survival of eggs from Echinococcus for nearly 41 months in an arid climate under ideal environmental conditions [40], the high prevalence of infection in dogs [41], and the large free-roaming dog population, mean that it is critical that the general public is made aware of the risk of echinococcosis from the consumption of potentially contaminated food or water.

It is not surprising that nearly all (72\%) participants in the current study had not heard of CE, but it was of concern that $57 \%$ do not know the mode of transmission of hydatid cysts, even after surgery for the condition. This is consistent with the results of other questionnaire surveys that have been conducted in Libya and Morocco [25,42], which found that most respondents have limited to no knowledge about echinococcosis and how it is transmitted. Currently, there is no control programme for echinococcosis or educational campaign in Basrah, which puts the community at a disadvantage regarding this important health issue.

The current study found that most participants followed poor practices concerning the disposal of offal unsuitable for human consumption. Offal from slaughtered livestock that is unsuitable for human consumption needs to be disposed of by burning, burying, or rendering to break the life cycle of Echinococcus $[43,44]$. Unfortunately, few respondents were aware of the risks associated with dogs and other carnivores having access to raw offal and how the latter can be involved in the transmission of Echinococcus. This outcome is similar to that reported in a survey of communities in Jordan, where waste from slaughtered animals was disposed in a manner allowing it to be accessed and eaten by domestic or stray dogs [36].

It is necessary for the Health Department of Basrah, in collaboration with the veterinary authorities, to develop and implement educational programmes on echinococcosis for farmers, pet owners, and the general public. Such programmes should provide information on the following: the need for regular deworming of dogs; improved hygiene for food preparation; slaughtering animals at their homes, including strict guidelines on how to dispose of infected offal; the life cycle of Echinococcus and how to stop it developing; and practices to minimise infection from dogs.

\section{CONCLUSION}

A questionnaire was administered to 50 patients with CE in Basrah, Iraq. Many patients owned dogs and there were large numbers of free-roaming dogs reported in the vicinity. Animals were slaughtered for consumption at many of the patients' homes. Few participants washed vegetables prior to eating them; understood how echinococcosis was transmitted to humans; or disposed of affected offal in a safe manner. It is strongly recommended that a control programme for CE is implemented to reduce the disease in humans, livestock, and dogs, and an educational campaign developed for the general public to reduce the incidence of this preventable disease.

\section{ACKNOWLEDGMENTS}

The authors would like to thank the Department of Health in Basrah for providing access to their records and the survey participants who completed the questionnaire. We would like to thank the Ministry of Higher Education in Iraq through a Ph.D. scholarship grant.

\section{CONFLICTS OF INTEREST}

The authors report no conflicts of interest. The authors alone are responsible for the content and writing of this article.

\section{REFERENCES}

[1] Deplazes P, Rinaldi L, Alvarez Rojas CA, Torgerson PR, Harandi MF, Romig T, et al. Global distribution of alveolar and cystic echinococcosis. Adv Parasitol 2017;95;315-493.

[2] Romig T, Deplazes P, Jenkins D, Giraudoux P, Massolo A, Craig PS, et al. Ecology and life cycle patterns of Echinococcus species. Adv Parasitol 2017;95;213-314.

[3] Acha PN, Szyfres B. Parasite zoonosis: helminthiases. In: Zoonoses and communicable diseases common to man and animals. 2nd ed. Washington: Pan American Health Organization; 1987, p. 716-35.

[4] Torgerson PR, Budke CM. Echinococcosis—an international public health challenge. Res Vet Sci 2003;74;191-202.

[5] Eckert J, Deplazes P. Biological, epidemiological, and clinical aspects of echinococcosis, a zoonosis of increasing concern. Clin Microbiol Rev 2004;17;107-35.

[6] Craig PS, McManus DP, Lightowlers MW, Chabalgoity JA, Garcia $\mathrm{HH}$, Gavidia CM, et al. Prevention and control of cystic echinococcosis. Lancet Infect Dis 2007;7;385-94.

[7] Moro P, Schantz PM. Echinococcosis: a review. Int J Infect Dis $2009 ; 13 ; 125-33$.

[8] Heidari Z, Mohebali M, Zarei Z, Aryayipour M, Eshraghian M, Kia E, et al. Seroepidemiological study of human hydatidosis in 
Meshkinshahr District, Ardabil Province, Iran. Iran J Parasitol 2011;6;19-25.

[9] Zhang T, Zhao W, Yang D, Piao D, Huang S, Mi Y, et al. Human cystic echinococcosis in Heilongjiang Province, China: a retrospective study. BMC Gastroenterol 2015;15;29.

[10] Galeh TM, Spotin A, Mahami-Oskouei M, Carmena D, Rahimi MT, Barac A, et al. The seroprevalence rate and population genetic structure of human cystic echinococcosis in the Middle East: a systematic review and meta-analysis. Int J Surg 2018;51;39-48.

[11] Communicable Disease Control Center. Communicable Diseases Control Guidelines. 2nd ed. Baghdad: Ministry of Health, Public Health Directorate; 2012.

[12] Maktoof AR, Abu Tabeekh MAS. Classification of endemicity of cystic echinococcosis in Basra Governorate-Iraq. Savant J Agric Res 2015;1;6-9.

[13] Thweni MM, Yassen LJ. Hepatic hydatidosis in man and livestock in Nassiriyah, Iraq. Inter J PharmTech Res 2015;7;310-14.

[14] Al-Yasari HF, Al-Shaiely AA, Al-Hassani NAA. A study of human hydatidosis: demographically and clinically in Hilla City. J Pure Appl Sci 2013;21;2873-82.

[15] Abdulhameed MF, Habib I, Al-Azizz SA, Robertson I. A retrospective study of human cystic echinococcosis in Basrah province, Iraq. Acta Trop 2018;178;130-3.

[16] Kern P, Menezes da Silva A, Akhan O, Müllhaupt B, Vizcaychipi KA, Budke C, et al. The echinococcoses: diagnosis, clinical management and burden of disease. Adv Parasitol 2017;96;259-369.

[17] NGO Coordination Committee for Iraq. Basrah Governorate profile; 2015. Available from: http://www.ncciraq.org/images/ infobygov/NCCI_Basra_Governorate_Profile.pdf. (accessed November 30, 2018).

[18] Kebede W, Hagos A, Girma Z, Lobago F. Echinococcosis/ hydatidosis: its prevalence, economic and public health significance in Tigray region, North Ethiopia. Trop Anim Health Prod 2009;41;865-71.

[19] Al-Qaoud KM, Craig PS, Abdel-Hafez SK. Retrospective surgical incidence and case distribution of cystic echinococcosis in Jordan between 1994 and 2000. Acta Trop 2003;87;207-14.

[20] Lahmar S, Rebaï W, Boufana BS, Craig PS, Ksantini R, Daghfous A, et al. Cystic echinococcosis in Tunisia: analysis of hydatid cysts that have been surgically removed from patients. Ann Trop Med Parasitol 2009;103;593-604.

[21] Hajipirloo HM, Bozorgomid A, Alinia T, Tappeh KH, Mahmodlou R. Human cystic echinococcosis in West Azerbaijan, Northwest Iran: a retrospective hospital based survey from 2000 to 2009. Iran J Parasitol 2013;8;323-6.

[22] Schantz PM, Wang H, Qiu J, Liu FJ, Saito E, Emshoff A, et al. Echinococcosis on the Tibetan Plateau: prevalence and risk factors for cystic and alveolar echinococcosis in Tibetan populations in Qinghai Province, China. Parasitology 2003;127;S109-S20.

[23] Possenti A, Manzano-Román R, Sánchez-Ovejero C, Boufana B, La Torre G, Siles-Lucas M, et al. Potential risk factors associated with human cystic echinococcosis: systematic review and meta-analysis. PLoS Negl Trop Dis 2016;10;e0005114.

[24] Kayouèche F, Chassagne M, Benmakhlouf A, Abrial D, Dorr $\mathrm{N}$, Benlatreche C, et al. Socio-ecological factors associated with risk of family hydatidosis in the wilaya of Constantine (Algeria) through interviews of urban and rural households. Rev Med Vet 2009;160;119-26.
[25] Buishia IE, Njoroge EM, Bouamra O, Craig PS. Canine echinococcosis in northwest Libya: assessment of coproantigen ELISA, and a survey of infection with analysis of risk-factors. Vet Parasitol 2005;130;223-32.

[26] Kilic B, Unal B, Semin S, Konakci SK. An important public health problem: rabies suspected bites and post-exposure prophylaxis in a health district in Turkey. Int J Infect Dis 2006;10;248-54.

[27] Macpherson CN. The epidemiology and public health importance of toxocariasis: a zoonosis of global importance. Int J Parasitol 2013;43;999-1008.

[28] Zhang W, Zhang Z, Yimit T, Shi B, Aili H, Tulson G, et al. A pilot study for control of hyperendemic cystic hydatid disease in China. PLoS Negl Trop Dis 2009;3; 534.

[29] Nasrieh MA, Abdel-Hafez SK, Kamhawi SA, Craig PS, Schantz PM. Cystic echinococcosis in Jordan: socioeconomic evaluation and risk factors. Parasitol Res 2003;90;456-66.

[30] Ito A, Urbani C, Jiamin Q, Vuitton DA, Dongchuan Q, Heath $\mathrm{DD}$, et al. Control of echinococcosis and cysticercosis: a public health challenge to international cooperation in China. Acta Trop 2003;86;3-17.

[31] Jiménez S, Pérez A, Gil H, Schantz P, Ramalle E, Juste RA. Progress in control of cystic echinococcosis in La Rioja, Spain: decline in infection prevalences in human and animal hosts and economic costs and benefits. Acta Trop 2002;83;213-21.

[32] Moro PL, Cavero CA, Tambini M, Briceño Y, Jiménez R, Cabrera L. Identification of risk factors for cystic echinococcosis in a peri-urban population of Peru. Trans R Soc Trop Med Hyg 2008;102;75-8.

[33] Dowling PM, Abo-Shehada MN, Torgerson PR. Risk factors associated with human cystic echinococcosis in Jordan: results of a case-control study. Ann Trop Med Parasitol 2000;94;69-75.

[34] Craig PS, Macpherson CN, Watson-Jones DL, Nelson GS. Immunodetection of Echinococcus eggs from naturally infected dogs and from environmental contamination sites in settlements in Turkana, Kenya. Trans R Soc Trop Med Hyg $1988 ; 82 ; 268-74$.

[35] Yaghan RJ, Bani-Hani KE, Heis HA. The clinical and epidemiological features of hydatid disease in Northern Jordan. Saudi Med J 2004;25;886-9.

[36] Qaqish AM, Nasrieh MA, Al-Qaoud KM, Craig PS, AbdelHafez SK. The seroprevalences of cystic echinococcosis, and the associated risk factors, in rural-agricultural, bedouin and semi-bedouin communities in Jordan. Ann Trop Med Parasitol 2003;97;511-20.

[37] Federer K, Armua-Fernandez MT, Gori F, Hoby S, Wenker C, Deplazes P. Detection of taeniid (Taenia spp., Echinococcus spp.) eggs contaminating vegetables and fruits sold in European markets and the risk for metacestode infections in captive primates. Int J Parasitol Parasites Wildl 2016;5;249-53.

[38] Kozan E, Gonenc B, Sarimehmetoglu O, Aycicek H. Prevalence of helminth eggs on raw vegetables used for salads. Food Control 2005;16;239-42.

[39] Aydın MF, Adıgüzel E, Güzel H. A study to assess the awareness of risk factors of cystic echinococcosis in Turkey. Saudi Med J 2018;39;280-9.

[40] Thevenet PS, Jensen O, Drut R, Cerrone GE, Grenóvero MS, Alvarez HM, et al. Viability and infectiousness of eggs of Echinococcus granulosus aged under natural conditions of inferior arid climate. Vet Parasitol 2005;133;71-7. 
[41] Beiromvand M, Akhlaghi L, Fattahi Massom SH, Meamar AR, Motevalian A, Oormazdi H, et al. Prevalence of zonnotic intestinal parasites in domestic and stray dogs in a rural area of Iran. Prev Vet Med 2013;109;162-7.

[42] El Berbri I, Ducrotoy MJ, Petavy A, Fassifihri O, Shaw AP, Bouslikhane M, et al. Knowledge, attitudes and practices with regard to the presence, transmission, impact, and control of cystic echinococcosis in Sidi Kacem Province, Morocco. Infect Dis Pov 2015;4;48.
[43] Acosta-Jamett G, Cleaveland S, Bronsvoort BM, Cunningham AA, Bradshaw H, Craig PS. Echinococcus granulosus infection in domestic dogs in urban and rural areas of the Coquimbo region, north-central Chile. Vet Parasitol 2010;169;117-22.

[44] Wachira TM, Macpherson CN, Gathuma JM. Release and survival of Echinococcus eggs in different environments in Turkana, and their possible impact on the incidence of hydatidosis in man and livestock. J Helminthol 1991;65;55-61. 